\title{
Estimate of outdoor thermal comfort zones for different climatic regions of Iran
}

\author{
GholamReza Roshan ${ }^{\mathrm{a}, *}$, Hanieh Saleh Almomenin ${ }^{\mathrm{a}}$, \\ Simone Queiroz da Silveira Hirashima ${ }^{\mathrm{b}}$, Shady Attia $^{\mathrm{c}}$ \\ a Department of Geography, Golestan University, Gorgan, Iran \\ ${ }^{\mathrm{b}}$ Department of Civil Engineering, Federal Center of Technological Education of Minas Gerais CEFET-MG, Av. Amazonas, 7675, CEP 30510-000 Belo \\ Horizonte, Minas Gerais, Brazil \\ ${ }^{\mathrm{c}}$ Sustainable Buildings Design Lab, Dept. UEE, Applied Sciences, Université de Liège, Belgium
}

\section{A R T I C L E I N F O}

\section{Keywords:}

Low and high thresholds

Thermal comfort indices

Bioclimatic conditions

Thermo-physiological

Urban planning

\begin{abstract}
A B S T R A C T
This study objective is to estimate high and low thresholds of the outdoor thermal comfort category for different thermal comfort indices in Iran. By using a statistical method that considers foure bioclimatic indices: SET*, PT, PET, and UTCI, the paper estimates their thermal comfort zone to gauge difference in terms of local climate. In this study, 154 stations were selected across the country and daily data period from 1995 to 2014 were considered. The results show that the estimated thermal comfort zones for the indices studied for Iran are: SET*, from 20.5 (BWh or Hot desert climate) to $25.5^{\circ} \mathrm{C}$ (BSh or Hot semi-arid climate); PT, from 15.9 (Cfa or Humid subtropical climate) to $19.1^{\circ} \mathrm{C}$ (Aw or Tropical wet and dry); PET, from 18.9 (BWh) to $22.5^{\circ} \mathrm{C}$ (Aw); and UTCI, from 18.5 (BWh) to $25^{\circ} \mathrm{C}$ (Csb or Warm-summer Mediterranean climate). A comparison between the original thresholds and estimated thresholds of each one of the four indices considered provides an insight to assist the future decision making of outdoor activities planning and design.
\end{abstract}

\section{Introduction}

The development of design parameters and a more evidence based understanding of outdoor thermal comfort can enhance the quality of outdoor spaces. Characterization of thermal comfort and the calibration of outdoor comfort assessment can contribute to better indoor comfort conditions and to the energy efficiency of buildings (Caldieron et al., 2011). Well-designed outdoor spaces can improve the economy, natural ecology, social well-being, and lifestyles of the local communities. The development of outdoors spaces with optimal thermal comfort has been shown to increase local real estate values, urban pedestrian and cycling levels (physical activities), and public transportation usage. Successful spaces that attract a large number of people have been found to attract businesses, workers, and residents (Nikolopoulou et al., 2010). Accordingly, since the mid-twentieth century, simple to complex bioclimatic indicators have been developed while their weaknesses and strengths were also demonstrated (Olgyay and Olgyay, 1954; Terjung, 1968; Fanger, 1972; Landsberg, 1972; Steadman, 1979; Mieczkowski, 1985; Gagge et al., 1986; Höppe, 1993; Taffé, 1997; Höppe, 1999; Parsons, 2003). The underlying point is that each one of the bioclimatic indices has been designed and modeled in a specific geographical condition, and for a specific community, along with its individual exclusive behaviors. Therefore, direct use of such indices for different climatic and geographical zones without calibration would have unclear outcomes. Specifically, most

\footnotetext{
* Corresponding author.

E-mail address: ghr.roshan@gu.ac.ir (G. Roshan).
} 
bioclimatic indices designed are pertinent to both Europe and to the U.S.A, whose regional characteristics differ, mainly in terms of climate, to those of the Middle East where Iran is located. This factor justifies the necessity to adjust these indices thermal comfort zones for different regions of Iran. Thus, combining the climatic and geographical factors for each given zone would result in a different understanding of thermal comfort conditions for the people of that community, where the evaluation of comfort conditions can be different from the comfort sensation of other individuals in other zones. The investigation of bioclimatic conditions of outdoor environment is influenced by different climatic elements, such as air temperature, relative humidity, wind speed and mean radiant temperature, which can be integrated and evaluated by the use of thermal indices. The scientific rigor requires the evaluation of the thermal component of an urban environment and the use of calibrated thermal comfort indices. The most precise method for the calibration of the thermal comfort indices for the local population considers the administration of forms/questionnaires simultaneously to the microclimatic parameters measurements. The indices calibration process aims to predict thermal sensation by determining representative intervals of thermal comfort conditions. Some researchers have already calibrated the thermal classes of PET for their specific climate, such as Lin and Matzarakis (2008) for Taiwan; Yahia and Johansson (2013) for Damascus, in Syria; Lai et al. (2014) for Tianjin, in China; Hirashima et al. (2016), for Belo Horizonte, in Brazil and Hirashima et al. (2018), also for Kassel and Freiburg, in Germany; Krüger et al., 2017 for Curitiba and Rio de Janeiro, in Brazil and also for Glasgow, UK; Salata et al. (2016) for Rome, in Italy and Kovács et al. (2016) for Hungary, among others. These studies emphasize that, in addition to the physiological factor of the human heat balance, thermal sensitivity and thermal comfort ranges vary among residents of different regions due to psychological and socio-cultural factors, e.g., there is a premise that thermal comfort zone in tropical regions might be shifted to high temperatures due to thermal experience of the population (Lin and Matzarakis, 2008; Hirashima et al., 2016; 2018).

In the present study, for the estimate of the approximate high and low thermal comfort thresholds of the thermal comfort zones of four different thermal comfort indices for different climatic regions in Iran, a statistical technique using macroscale data from meteorological stations was used. This method is based on the consideration of four comfort zones established by four different bioclimatic thermal comfort indices:

- New Standard Effective Temperature (SET*) (Gagge et al., 1967),

- Perceived Temperature (PT) (Jendritzky et al., 1979; apud Jendritzky and Nübler, 1981),

- Physiological Equivalent Temperature (PET) (Höppe, 1999) and

- Universal Thermal Climate Index (UTCI) (ISB, 2001; Bröde et al., 2010).

In terms of human thermal comfort in urban spaces, it is less exact than the calibration process, once it does not consider urban users responses regarding thermal sensation (no forms/questionnaires are administered) nor does it consider microscale measurement data. But it is a process that is cheaper, faster and easier to be carried out because no great work team is required. One of the benefits of these methods is that only by accessing macroclimatic data from meteorological stations; we can achieve the desired goals on estimating bioclimatic comfort categories in a short time.

The method presented in this paper and the indices calibration process differs significantly in terms of accuracy. Nevertheless, they are complementary and can be used together. Due to the availability of macroscale data and the need to consider the comfort zone in the city planning processes, it is important to rely on a rough estimate of a comfort zone. The use of our proposed methodology in this article allows us to rely on a rough estimate of comfort zones because the studies main focus is on comfort zone (not in the entire scale, what happens in the calibration studies). Since the comfort categories used to define the max/min new comfort thresholds in this study are "universal", the comfort zones estimated will always be more restrictive than the original range of the considered indices. The comfort categories will not really correspond to the real perception of comfort by Iranians, but it is an estimate. If a calibration of the PET index (for example) is performed for some city in Iran, a wider or narrower comfort interval, or maybe a comfort range displaced to colder or hotter conditions, may result, when compared to the original ranges of this index, due to the adaptive processes of the local population.

Based on the climatology model, defining and estimating the comfort boundaries of each station or geographic region is affected by the repeating pattern and frequency of the occurrence of days with thermal comfort. In other words, according to climatic diversity of different geographical areas, each station has a different experience of the frequency of days with thermal comfort, so that it is possible that in most cases a station experiences these comfort conditions in high humidity and low temperatures. But some stations, considering their prevailing climatic conditions, experience their maximum frequency of the occurrence of days with comfort at higher temperatures with lower relative humidity. The outcome of this issue is the compatibility of people in each area with its prevailing weather conditions. As one can deduce, the person who lives in cold and dry weather conditions has a different experience from the comfort days compared with someone who is living in hot and humid climate. The cause of this different feeling about bioclimatic conditions is the existence of different adaptive climatic behavior in those climatic zones.

Considering the previous discussion, the objective of the present work is to determine a scope of comfort boundaries in which maximum repetition and its frequency for each station has occurred. In other words, by eliminating rare cases of thermal comfort occurred at each station, we are seeking to estimate the dominant model of thermal comfort and to introduce a new boundary within the scope of thermal comfort. The distinctive feature in this study is that it investigates the most applicable bioclimatic thermophysiological indices, which the condition of body energy balance refers to. The results of this study can have useful application parallel to regional and city planning. 


\section{Materials and methods}

In order to determine the high and low outdoor thermal comfort thresholds of different bioclimatic and thermo-physiological indices for different regions of Iran, data from the meteorological stations were used. Meteorological station reports for the last twenty-year statistical period were used. To present the most perfect daily data, 154 stations of Iran were selected. In addition, variables, including dry air temperature in degrees Celsius, relative humidity in percent or vapor pressure in hectopascal, wind speed in meters per second, and cloudiness in okta for the years from 1995 to 2014, were investigated. Out of these selected stations, 5\% presented data gap to the amount of $3 \%$ data gap was rebuilt by using adjacent stations, on the basis of linear regression method, according to recommendations of the Meteorology Organization of Iran. Fig. 1 shows the geographical location and the climatic zone classification of all meteorological stations used in this study.

In this work, four well-known thermal comfort indices were selected to be studied: New Standard Effective Temperature (SET*) (Gagge et al., 1967), Perceived Temperature (PT) (Jendritzky et al., 1979; apud Jendritzky and Nübler, 1981), Physiological Equivalent Temperature (PET) (Höppe, 1999) and Universal Thermal Climate Index (UTCI) (ISB, 2001; Bröde et al., 2010). These indicators were chosen because all of them have been used for urban and outdoor thermal conditions evaluation, being expressed in the same unit, in Celsius Degree $\left({ }^{\circ} \mathrm{C}\right)$. Another reason, for the use of these four indices is the possibility to compare the results of the 4 indicators. These indices differ in terms of the complexity of the thermo-physiological balance model in which they are based. UTCI is based on a multi-node model of human heat balance (Bröde et al., 2010).

In this study, RayMan software ${ }^{1}$ was used to determine four reliable bioclimatic indices: SET*, PT, PET, and UTCI values. The description of this model is available in Matzarakis et al. (2007, 2010). One of the important features of this model is simulating the short and long wave radiation flux densities from the three-dimensional surroundings in simple and complex environments. The final output of the model is the mean radiant temperature of the environment, which is among the most important components in calculating PET and other indices. The climatic variables needed for RayMan to calculate above bioclimatic indices included Meteorological variables, such as dry air temperature, in degrees Celsius; relative humidity, in percent or vapor; Pressure, in hectopascal; wind speed, in meters per second; and cloudiness, in oktas.

Mean daily thermal comfort indices values were calculated using the RayMan software (Matzarakis et al., 2007, 2010). The thermo-physiological parameters heat resistance of clothing (in clo units) and activity of humans (in W) required to run RayMan, were set to the values $80 \mathrm{~W}$ and 0.9 clo. These values were related to a standardized male person of $1.75 \mathrm{~m}$ of height, $75 \mathrm{~kg}$ of weight and 35 years of age. Experience has shown that the differences in the gender of the male (male/female) will not cause a significant difference in outcomes, and this difference is very slight and negligible. By using these values, the standard person is characterized by a working metabolism of light activity in addition to basic metabolism and heat resistance due to clothing. For our research methodology illustrated in Fig. 2, we recommend that these four indicators could be considered together, in order to define approximate thermal comfort zones for each one of the climatic regions of Iran (Roshan et al., 2016a; Roshan Gh and Attia, 2017). Table 1 shows the categories of thermal sensation for each of these indices, set up by their inventors for universal applications. In this study, we are going to concentrate on their comfort category.

In a preparatory stage, data of 7305 days belonging to the statistical period from 1995 to 2014, from the mentioned 154 meteorological stations, were used. The daily numerical value (output) for each one of the four thermal comfort indices was calculated. Days were only considered as comfortable when the mean daily values in all indices lied within the comfort range as defined for each index. In order to separate the days in comfort category and the days out of comfort category, these days were replaced by codes: 1 and zero, respectively. Subsequently, the present method was conducted in three main steps.

At the first step, the days in which the indices values were out of the comfort category for one or more of the four indices considered were deleted, because the purpose of this method is to consider the coincidence of comfort days event for the four indices together. Then, the thermal comfort condition for each index were classified in comfort categories. We used this methodology because, as mentioned before, the aim of this work is to combine different bioclimatic indices as theoretical basis in determining thermal comfort conditions. Thus, at this stage, a group of comfort days event (classified only based on either one of the indices) was removed for each of the indices. In general, only a temporal series of frequency of comfort days of all indices was obtained for each of the meteorological stations considered. In the present work, these days commonly comfortable in all indices are known as thermal comfort days.

In the second step, an analysis was carried out by considering only the days that passed on the previous stage filter. There were only thermal comfort days, which satisfied thermal conditions for all four indices. For this derived temporal series, the output of standard deviation of each index considered was calculated. For each station, this process and other following processes had to be conducted separately during this stage, to determine the low and high limit of estimated comfort category of each thermal comfort index. For each one of the four indices, the mean standard deviation of low and high thresholds of the established comfort category was determined. In the first step, days were only considered as comfortable when the mean daily values in all indices lied within the comfort range as defined for each index. In the second step, standard deviation of each index considered was calculated by considering only the comfortable days that passed on the previous stage filter. Therefore, at the end of the second step, the estimated thresholds of comfort category were recognized. It can be briefly said that the thresholds of estimated comfort category were determined from doing normal distribution zone ( $90 \%$ of central data) over a period of time - the days which have been determined as comfort day by four indices.

\footnotetext{
${ }^{1}$ Available at: http://www.mif.uni-freiburg.de/rayman/intro.htm.
} 


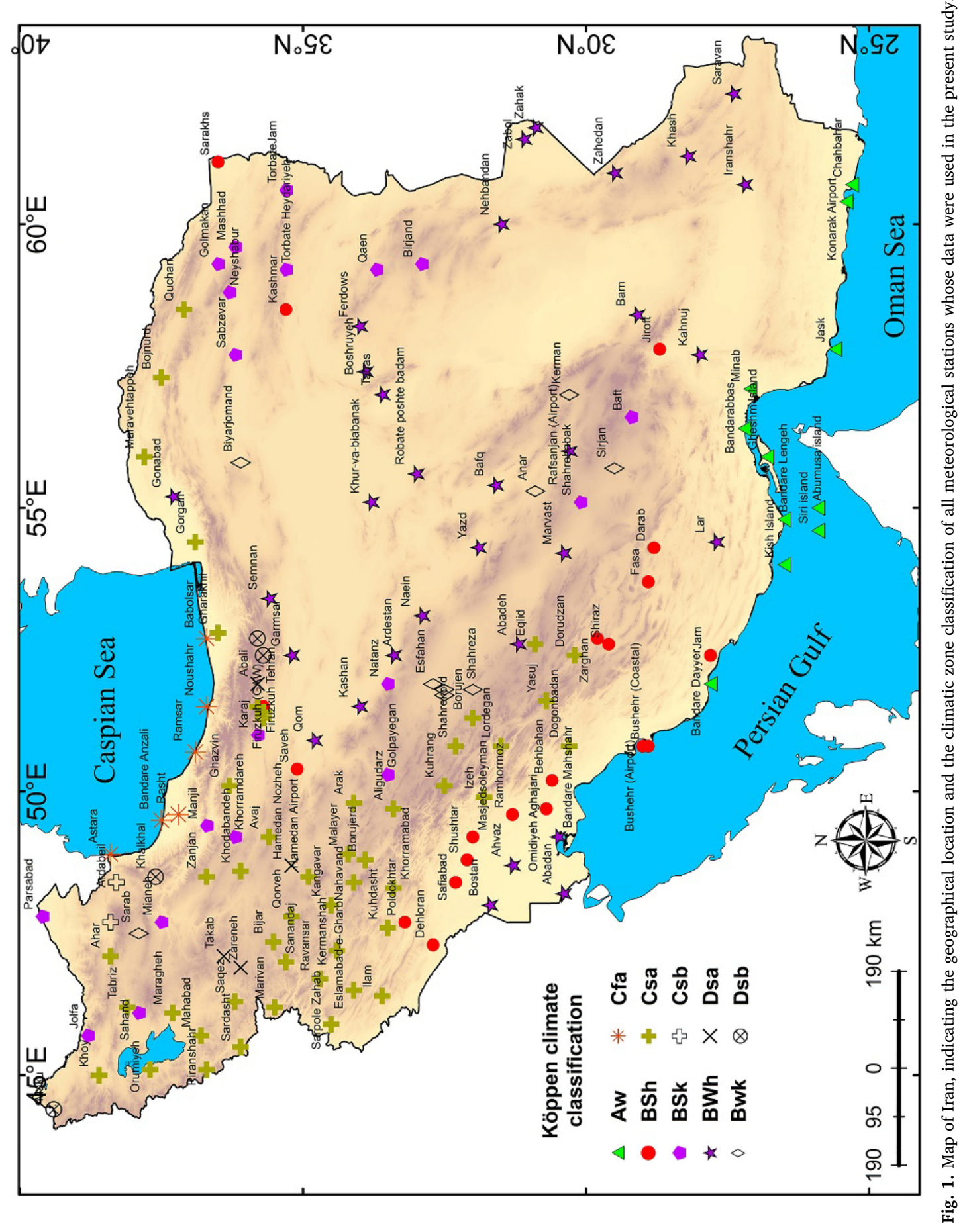




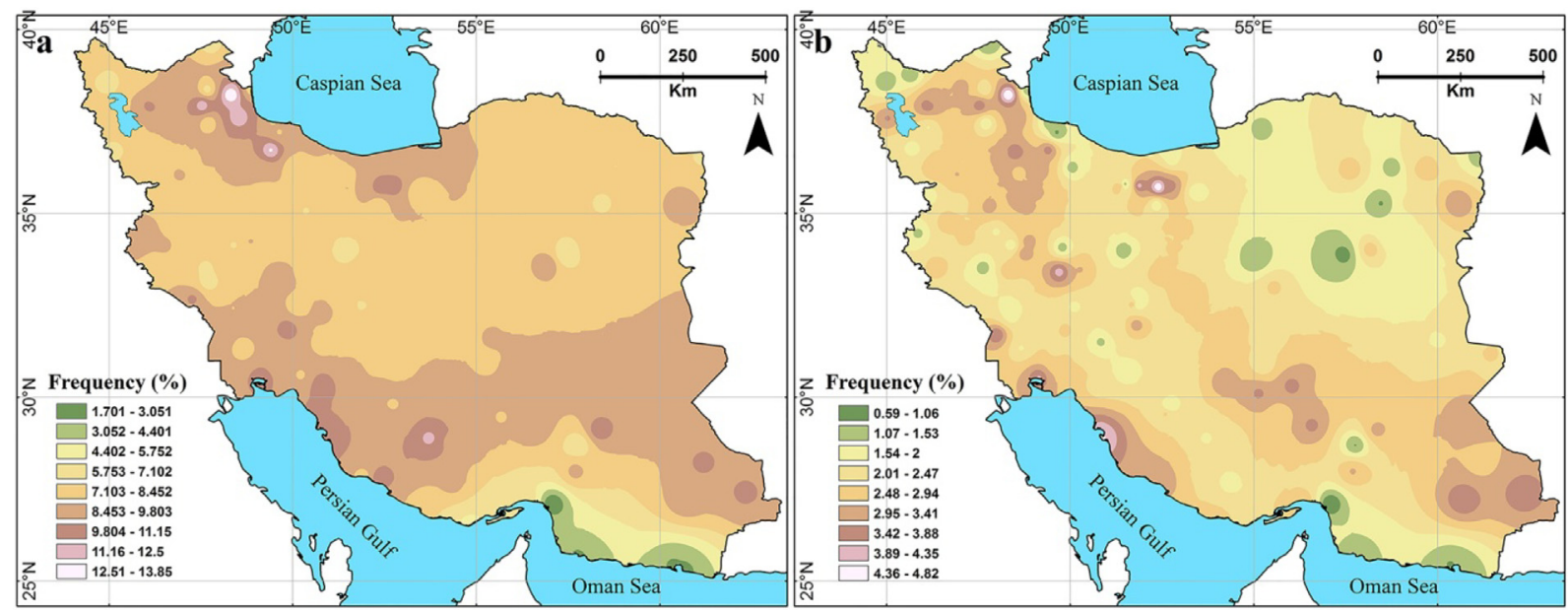

Fig. 2. Flowchart of Various Stages Involved in Research Study.

Table 1

Original categories of thermal sensation/thermal stress of the four indices considered.

\begin{tabular}{|c|c|c|c|c|}
\hline Index thermal sensation/stress & $\begin{array}{l}\text { SET }^{*}\left({ }^{\circ} \mathrm{C}\right) \text { (Gagge et al., } \\
1986)\end{array}$ & $\begin{array}{l}\text { PT }\left({ }^{\circ} \mathrm{C}\right) \text { (Staiger et al., } \\
2012 \text { ) }\end{array}$ & $\begin{array}{l}\text { PET }\left({ }^{\circ} \mathrm{C}\right) \text { (Matzarakis and Mayer, } \\
1996)\end{array}$ & $\begin{array}{l}\text { UTCI }\left({ }^{\circ} \mathrm{C}\right) \text { (after Bröde et al., } \\
\text { 2012) }\end{array}$ \\
\hline Extreme cold stress & - & $-39>$ & - & $<-40$ \\
\hline Very strong cold stress & - & -39 to -26 & - & -27 to -40 \\
\hline strong cold stress & - & -26 to -13 & $<4$ & -13 to -27 \\
\hline Moderate cold stress & - & -13 to 0 & $4-8$ & 0 to -13 \\
\hline Slight cold stress & $<17$ & 0 to 20 & $8-18$ & 9 to 0 \\
\hline Comfortable & $17-30$ & 20 to 26 & 18 to 23 & 9 to 26 \\
\hline Moderate heat stress & $30-34$ & 26 to 32 & $23-35$ & 26 to 32 \\
\hline Strong heat stress & $34-37$ & 32 to 38 & $35-41$ & 32 to 38 \\
\hline Very strong heat stress & $>37$ & $>38$ & $>41$ & 38 to 46 \\
\hline Extreme heat stress & - & - & - & $>46$ \\
\hline
\end{tabular}

In fact, based on this action, two new thresholds of thermal comfort were specified for each thermal comfort index, which defines the comfort zone of this new threshold, for the locality of each meteorological station considered. Ninety percent of these comfort days events were included towards the center or mean of the comfort days of the considered stations. In other words, the extreme comfort days from the entire comfort data were left out and the focus was on the data that had the most frequency of comfort events. The approximate maximum and minimum values of the comfort category were established. The maximum and minimum values were set based on the four thresholds of comfort categories set up beforehand. As an example for the PET index, the estimate of the approximate high and low values of the comfort zone resulted only in values between the intervals of 18 to $23^{\circ} \mathrm{C}$. Therefore, the objective of this study was to remove the rare status of thermal comfort and the access to the thresholds that result from dominant patterns of events. For that, the minus and plus average of the standard deviation facilitated our access as expected. In the end of the second step, a periodical series of frequency of comfort days event would result that the frequency of this periodical series would definitely be different in comparison to the periodical series of the first step. By introducing the estimated thresholds of the comfort category in the end of the second step, the zone of the category low and high thresholds became narrower than the threshold of the first step comfort category. As a result some of the days removed, which were introduced in the first step as the comfort day earlier was removed. Finally, during the third step, the frequency difference of the comfort days events was evaluated. By using Kriging interpolation surface-making plans were designed and provided.

To generate bioclimatic maps, 154 weather stations were used. Before the production of the maps, training and testing method in the Geostatistical model were used. In orders to assess the accuracy of the produced maps, $80 \%$ of the stations were separated as training and $20 \%$ as test stations. Thus, using the Kriging method and based on $80 \%$ of the stations, a $80 \%$ map was generated. Finally, based on $20 \%$ of the remaining stations, validation was performed. Then, the calculated error was estimated from the difference between the observations and the predicted data and was turned into absolute error. In the following the ratio of absolute error to the observations was calculated. Based on this, the average relative error was $6.4 \%$. Therefore, it can be claimed that the accuracy of the generated map with a resolution of 0.05 geographical degrees is equal to $93.6 \%$, which is acceptable. The methodology of present work is almost the same methodology used by Roshan (2017) and Roshan Gh and Attia (2017). 
Table 2

Thermal comfort zones estimated, considering all stations of Iran, for each one of the indices considered, and other statistics.

\begin{tabular}{llll}
\hline Thermal Comfort Thresholds & SET* $\left({ }^{\circ} \mathrm{C}\right)$ & PT $\left({ }^{\circ} \mathrm{C}\right)$ & UTCI $\left({ }^{\circ} \mathrm{C}\right)$ \\
\hline Comfort range estimated & 20.5 to 25.5 & 15.9 to 19.1 & 18.9 to 22.5 \\
Mean of Max & 24.2 & 17.8 & 22.1 \\
Mean of Min & 21.9 & 16.1 & 18.4 to 25 \\
Max & 25.4 (Hasanabad Darab) & 19.1 (Siri Island) & 23.6 \\
Min & 20.4 (Ahvaz) & 15.9 (Bandar Anzali) & 20.6 \\
\hline
\end{tabular}

\section{Research findings}

\subsection{Determination of low and high thresholds of estimated comfort category}

In this part of the study, the low and high thresholds of the estimated comfort category for the 154 study stations, located in different climatic regions of Iran, are presented. The mean thermal comfort zones estimated, considering all stations of Iran, for each one of the indices considered, as well as other statistics, are shown in Table 2.

On the basis of PET, the minimum of high estimated threshold with $21.63^{\circ} \mathrm{C}$ belongs to Ahvaz, and Chabahar with $22.51{ }^{\circ} \mathrm{C}$ has experienced maximum high threshold in Iran. The outputs show that 7.14 and $92.86 \%$ of the study stations are respectively in 21.63 to $22{ }^{\circ} \mathrm{C}$ categories and 22.01 to $22.51{ }^{\circ} \mathrm{C}$. Hence, maximum concentration of the high PET estimated threshold relates to the second category of frequencies.

About high threshold index SET*, the maximum high threshold of $25.44^{\circ} \mathrm{C}$ belongs to Hasanabad Darab and maximum high threshold with $23.12{ }^{\circ} \mathrm{C}$ relates to Abumosa Island. Yet, the outputs of this part show that 7.14 and $25.32 \%$ of frequency of stations relating to high threshold $23.12^{\circ} \mathrm{C}$ to $23.50{ }^{\circ} \mathrm{C}$ and $23.51{ }^{\circ} \mathrm{C}$ to $24{ }^{\circ} \mathrm{C}$ and also $29.22{ }^{\circ} \mathrm{C}$ and $38.31 \%$ of frequencies belong to categories of $24.01{ }^{\circ} \mathrm{C}$ to $24.50{ }^{\circ} \mathrm{C}$; and finally $24.51{ }^{\circ} \mathrm{C}$ to $25.44^{\circ} \mathrm{C}$ respectively.

The high threshold UTCI varies from the least $21.66^{\circ} \mathrm{C}$ to the most $25.03^{\circ} \mathrm{C}$ for stations of Kashan and Ardebil respectively. If the frequency of high estimated threshold is investigated for UTCI in three categories, it is observed that $9.09 \%$ of frequency of the stations was pertinent to the category $21.66^{\circ} \mathrm{C}$ to $23^{\circ} \mathrm{C}$ and $64.94 \%$ of frequencies belong to the category $23.01{ }^{\circ} \mathrm{C}$ to $24{ }^{\circ} \mathrm{C}$ and consequently for category $24.01{ }^{\circ} \mathrm{C}$ to $25.03{ }^{\circ} \mathrm{C}, 25.97 \%$ stations, frequency are included.

The outputs for the PT index are indicative of high threshold index PT from the least $17.31{ }^{\circ} \mathrm{C}$ to the most $19.10^{\circ} \mathrm{C}$ for Firouzkoh and Siri Island respectively. For this index, the station's frequency for high threshold of the estimated category is $17.31{ }^{\circ} \mathrm{C}$ to $18{ }^{\circ} \mathrm{C}$ and it includes $72.08 \%$ and for $18.01{ }^{\circ} \mathrm{C}$ to $19.10^{\circ} \mathrm{C}$, and it includes $27.92 \%$ from the study stations.

Among other findings in this research, are the results about the low threshold of estimated comfort category. The findings show that the general mean of the estimated low threshold for PET, and SET* is 19.64 and $21.90^{\circ} \mathrm{C}$ respectively; and this general means for UTCI and PT includes 20.65 and $16.16^{\circ} \mathrm{C}$. For the PET index, the zone of non- estimated comfort category regarding high threshold $23^{\circ} \mathrm{C}$ and low threshold $18{ }^{\circ} \mathrm{C}$, number 5 is obtained in the widest possible status. This zone belongs to stations of Zarghan Fars and Babolsar to the amount of 2.82 and 2.80 respectively. Whereas the zone of estimated comfort category with the amounts 2.14 and $2.26^{\circ} \mathrm{C}$ belonging to Zanjan and Tabriz stations are observed in the thinnest status possible. Yet, findings of the study showed that the zone of estimated comfort category based on the findings of all stations varies from the least $18.92{ }^{\circ} \mathrm{C}$ to $22.51{ }^{\circ} \mathrm{C}$. If we pay attention

Table 3

Low and high thresholds estimated for the four bioclimatic indices.

\begin{tabular}{|c|c|c|c|c|c|c|c|c|}
\hline \multirow[t]{2}{*}{ Stations } & \multicolumn{4}{|c|}{ High thresholds } & \multicolumn{4}{|c|}{ Low thresholds } \\
\hline & PET & SET* & UTCI & PT & PET & SET* & UTCI & PT \\
\hline Abumusa Island & 22 & 23.12 & 24.38 & 18.88 & 19.34 & 20.81 & 21.6 & 16.35 \\
\hline Ahvaz & 21.63 & 23.38 & 23.41 & 18.18 & 18.92 & 20.45 & 20 & 15.98 \\
\hline Ardebil & 22.21 & 24.11 & 25.03 & 18.08 & 19.77 & 21.91 & 22.46 & 16.08 \\
\hline Babolsar & 21.94 & 24.74 & 23.95 & 18.27 & 19.14 & 22.32 & 20.32 & 16.01 \\
\hline Bandarabbas & 22.44 & 23.95 & 24.31 & 18.41 & 20.02 & 21.74 & 22.34 & 16.38 \\
\hline Chahbahar- & 22.51 & 23.58 & 24.41 & 18.51 & 19.98 & 21.44 & 22.12 & 16.29 \\
\hline Firuzkuh (GAW) & 22.1 & 23.94 & 23.64 & 17.31 & 19.77 & 21.58 & 21.3 & 16.06 \\
\hline Hasanabad Darab & 22.23 & 25.44 & 22.32 & 18.2 & 19.59 & 22.8 & 19.43 & 16.37 \\
\hline Jask & 22.47 & 23.45 & 24.59 & 18.92 & 20.16 & 21.61 & 22.58 & 16.67 \\
\hline Jolfa & 22.22 & 24.81 & 23.61 & 18 & 19.63 & 22.37 & 19.67 & 16.28 \\
\hline Khash & 22.1 & 23.95 & 23.58 & 17.55 & 19.62 & 21.63 & 20.41 & 16.16 \\
\hline Qorveh & 22.14 & 23.84 & 23.82 & 17.33 & 19.82 & 21.49 & 21.32 & 16.14 \\
\hline Siri island & 22.04 & 23.14 & 24.42 & 19.1 & 19.4 & 20.84 & 21.48 & 16.47 \\
\hline Tabriz & 22.27 & 23.72 & 24.23 & 17.59 & 20.01 & 21.85 & 22.2 & 16.2 \\
\hline Yazd & 22.19 & 23.83 & 23.44 & 17.39 & 19.81 & 21.71 & 20.97 & 16.18 \\
\hline Zanjan & 22.16 & 24.08 & 23.97 & 17.42 & 20.02 & 22.09 & 21.73 & 16.2 \\
\hline Zarqan & 22.14 & 24.9 & 22.8 & 17.74 & 19.32 & 22.31 & 19.12 & 16.11 \\
\hline
\end{tabular}


to Table 3, this issue is vividly understood: the skew of estimated comfort category for most stations tends to a greater amount. In other words, the low estimated threshold for most stations is far more from the base $18^{\circ} \mathrm{C}$, while the distance of high estimated threshold shows less distance towards the number $23^{\circ} \mathrm{C}$.

For the index SET*, the zone of non-estimated comfort band, with respect to low and high threshold between $17^{\circ} \mathrm{C}$ and $30^{\circ} \mathrm{C}$, is the number $13^{\circ} \mathrm{C}$, which is considered as the estimated comfort zone for Iran (from $20.45^{\circ} \mathrm{C}$ to $25.44^{\circ} \mathrm{C}$ ). On the other hand, in the broadest possible status for the band zone SET* with $2.94^{\circ} \mathrm{C}$ is relatiedto Ahvaz and Jask. Ahvaz and Jask has devoted the thinnest estimated band zone of $1.84^{\circ} \mathrm{C}$. If we refer to Table 3 , it is inferred that the distance of low estimated threshold towards number $30{ }^{\circ} \mathrm{C}$ for most stations is more than the distance of low estimated thresholds of the number $17^{\circ} \mathrm{C}$. Regarding the difference in the general mean of high estimated threshold for all stations in relation to the number $30{ }^{\circ} \mathrm{C}$, the obtained number was $4.90{ }^{\circ} \mathrm{C}$. This issue indicates greater skew of high estimated thresholds towards the center of comfort zone, in comparison to low estimated threshold.

For UTCI, the main zone of comfort band, which is based on high and low threshold of comfort category including $26^{\circ} \mathrm{C}$ and $9{ }^{\circ} \mathrm{C}$, the number $17^{\circ} \mathrm{C}$ is obtained. However, this band zone, with respect to the lowest threshold to the amount of $18.47^{\circ} \mathrm{C}$ and its maximum threshold for Iran to the amount of $25.03{ }^{\circ} \mathrm{C}$, shows the number $5.56{ }^{\circ} \mathrm{C}$. Yet, maximum and minimum extent of the estimated band zone with the amount 3.94 and $1.97^{\circ} \mathrm{C}$ belongs to Jolfa stations and Northwest of Iran and Bandar Abbas in the Southern Coast of Iran.

The result of Table 3 shows that the low threshold of the estimated comfort category is sharply far from the number $9{ }^{\circ} \mathrm{C}$ and the skew of estimated comfort for the selected stations tends to greater amounts or high threshold. In the end, we can refer to the changes of the band zone for the PT index. According to the non-estimated comfort category, the zone of this band from the least 0 to its maximum to the amount of $20^{\circ} \mathrm{C}$ shows an extent equal to $20^{\circ} \mathrm{C}$. However, by inferring this, this zone for Iran varies from $15.93{ }^{\circ} \mathrm{C}$ to $19.10^{\circ} \mathrm{C}$. The findings of this study show that the maximum zone of the estimated comfort band of $2.63^{\circ} \mathrm{C}$ belongs to Siri Island. Two stations namely Qorveh and Yazd have commonly experienced the thinnest comfort band zone to the amount of $1.20^{\circ} \mathrm{C}$. For this index, with respect to Table 3, it is observed that the categorical skew of estimated comfort for all stations tends towards the high threshold of $20^{\circ} \mathrm{C}$. Low estimated thresholds in relation to zero are much greater than the high estimated thresholds in relation to the number $20^{\circ} \mathrm{C}$.
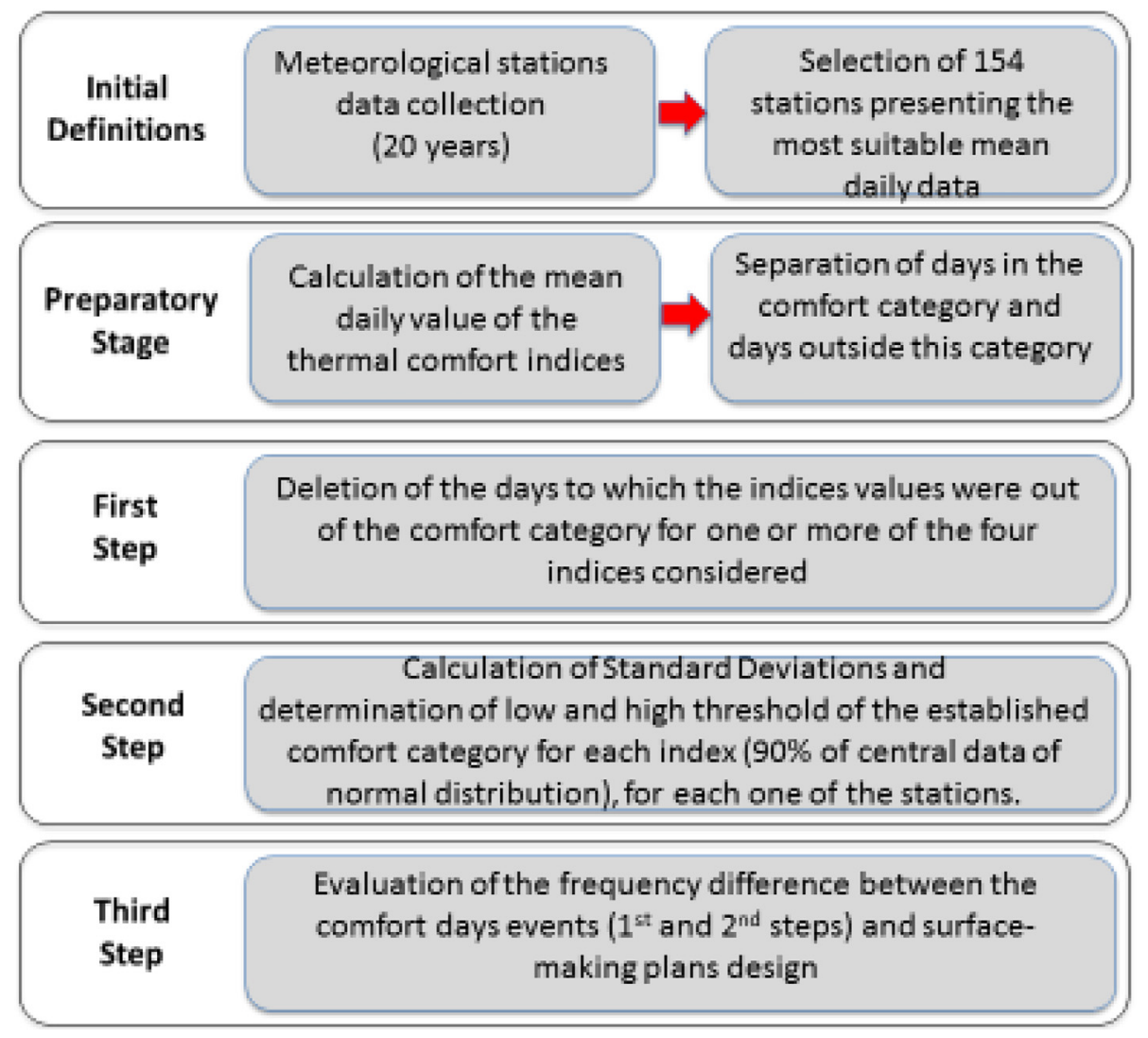

Fig. 3. Frequency difference of comfort day's event of the first step from comfort day's frequency of the second step for different month of the year. 


\subsection{Frequency difference survey of comfort day event based on the original threshold of each one of the four indices considered in comparison} to the estimated threshold

In this part of the study, the frequency difference of comfort day events of the first step from the frequency of the comfort days of the second step was estimated and its results were presented by means of Fig. 3. With respect to the estimated thresholds of comfort category in the second step, some of the comfort days that were based on the first step of the comfort category would be removed. According to Fig. 3, areas showing variance of zero are, in fact, zones that have not formerly had any experience on the comfort event at the first step. Therefore, it can be easily seen that in the thresholds outputs of the second step, their amount is zero or in other words, without diminishing changes. In other parts, spatial and temporal changes are indicatives of how many days for each given month would be getting out of the comfort category.

For the winter season in Iran, the maximum frequency of cold stress is observed everywhere in the country, except for the southern part, where people experience thermal comfort. So, for January, the outputs show that $36.36 \%$ of frequency of stations with most locations is on the half northern of the country, presents the amount zero. In other words, these areas have not experienced the comfort event at the first step. So by administering the second step, no change in the comfort day event is observed. In January, with respect to administering estimated zone of comfort category, $13.63 \%$ of stations have experienced some decrease in comfort days ( $>100$ days) and their main concentration relates to the Southern Coast of Iran. Among these stations, Hasanabad Darab and Lar, with the amounts 172 and 157 decreases have devoted the greatest deletion of comfort days to them (Fig. 3a). In February, 19.48\% of the stations have had no experience of comfort event. Most of these areas are in the Northwest of the Zagros Mountains and the Northeast of Iran. Too in February, 13.63\% of stations witness more than hundred days of their comfort days. Their main zones are observed in the Northern Coast of the Persian Gulf and Kaveer field of Iran. In February, the decrease of comfort days to the amount 140 and 136 days is seen for the stations Dogonbadan and Tabas (Fig. 3b). In the last month of winter including Mars, in spite of that no comfort event for the two stations Behbahan and Zarrineh happened, but with these interpretations, among the two main zones northwest and the other Northern Coast of the Oman Sea - show the least omission of comfort days. In Mars, the greatest decreasing changes relate to the half eastern of the country, where Fasa in the Fars province with decreasing changes 176 days devoted maximum decreasing record to them (Fig. 3c).

With the start of Spring, in April, May, June, 5.19, 20.12 and 46.1\% of stations experienced no frequency of event of bioclimatic comfort category. It is interesting to say that the main cores of the areas having no experience of comfort event, first for April as concentrating on the Northern Coast of Persian Gulf, then in May. Too, the Half- Northern and Center of Iranhave consequently covered in June. In most zones of Iran, this condition is seen except for the Northwest of the Country. But in this season, for April, $15.58 \%$ of stations lost $>100$ thermal comfort day based on the estimated threshold. But for May, this amount leads to number 13 and for June to $1 \%$ of stations. Generally, with respect to being minimum frequency of the threshold comfort days event for the South Coast, and half of the Central and Eastern Iran, so the most decreasing changes of removing comfort days belongs to the Northwest of Iran, and the Zagros Mountains areas (Fig. 3f to d).

Summer in Iran, is known as the hot season, where in most zones there is some evidence of thermal stresses event. That's mostly in the South Coast band and north of Iran, due to a combination of the resulted humidity coming from reservoir and high temperatures. This condition creates undesirable bioclimatic condition, thus thermal discomfort event is observed. The outputs of this part of the research show that the summer season is the least favorable season among other seasons in the view of bioclimatology. In July $76.62 \%$, in August $66.88 \%$ and for September 35\% of stations were without benefit from new thermal comfort condition. As it is observed from Fig. 4i, as late summer arrives, the thermal comfort zone was expanded slightly in the northern areas of Iran. Yet, the Central and Southern coast of Iran experiences unfavorable bioclimatic conditions. In this season, the maximum decreasing changes of thermal comfort days based on estimated thresholds belong to the Northwest of Iran with the focus on Ardebil station, and still, high areas of Alborz with a focus on Firuzkoh and Zarrineh in Kordestan Province. Thus for months of this season, a few decreasing stations show $>100$ days (Fig. 3i to g).

In the autumn season compared with summer, the comfort day event increased because of only $3.5,15$ and $18.83 \%$ of stations in the months, October, November and December had no thermal comfort event. These areas, in terms of spatial and temporal distribution in October in Persian Gulf Coast and Oman Sea, have concentrated on Dasht-e Kavir, in November. The areas of thermal comfort maximum in two main cores of Persian Gulf Coasts and Oman Sea and a core zoomed out on Dasht-e Kavir, and consequently in December. The minimum of comfort events is observed for altitudes of Northwest Zagros and altitudes of the northeast. On the other hand, the maximum decreasing changes of comfort days with respect to the estimated thresholds for October is seen in the northwest areas. In November, a small core in the northeast and the Caspian Sea Coast, witness the maximum changes in the end of autumn. For October, $24.67 \%$ of stations lost $>100$ days of their own thermal comfort day on the basis of the estimated threshold. For November, this amount led to $20 \%$ and for June to $13 \%$ of stations (Fig. 31 to j).

In general, and based on the entire daily data from 1995 to 2014, Ardebil and Minab, with 13.83 and 1.70\%, have spent maximum and minimum of their own days on comfort condition. But among the study stations, only $11 \%$ of stations spent between 10 and $13.85 \%$ of their own days on comfort category. Therefore, based on the process of the first step of research, the spatial distribution of minimum days accompanying the comfort category event belongs to the Northern Coast of the Oman Sea and its maximum relates to the west and south parts of the Caspian Sea (Fig. 4a). It is worth nothing that by administering the estimated threshold of thermal comfort category or conducting process of the second step of the research, the comfort day frequency was severely diminished. According to this, the frequency fluctuations of comfort days are related to the estimated threshold from the least $0.6 \%$ to the maximum of $5 \%$ for the stations of Minab and Bushehr (coastal). As it is shown from Fig. 4b, the frequency distribution of thermal comfort days regards the estimated threshold. In the Southwest and Northwest areas, some small zones of Northern Coasts of the 


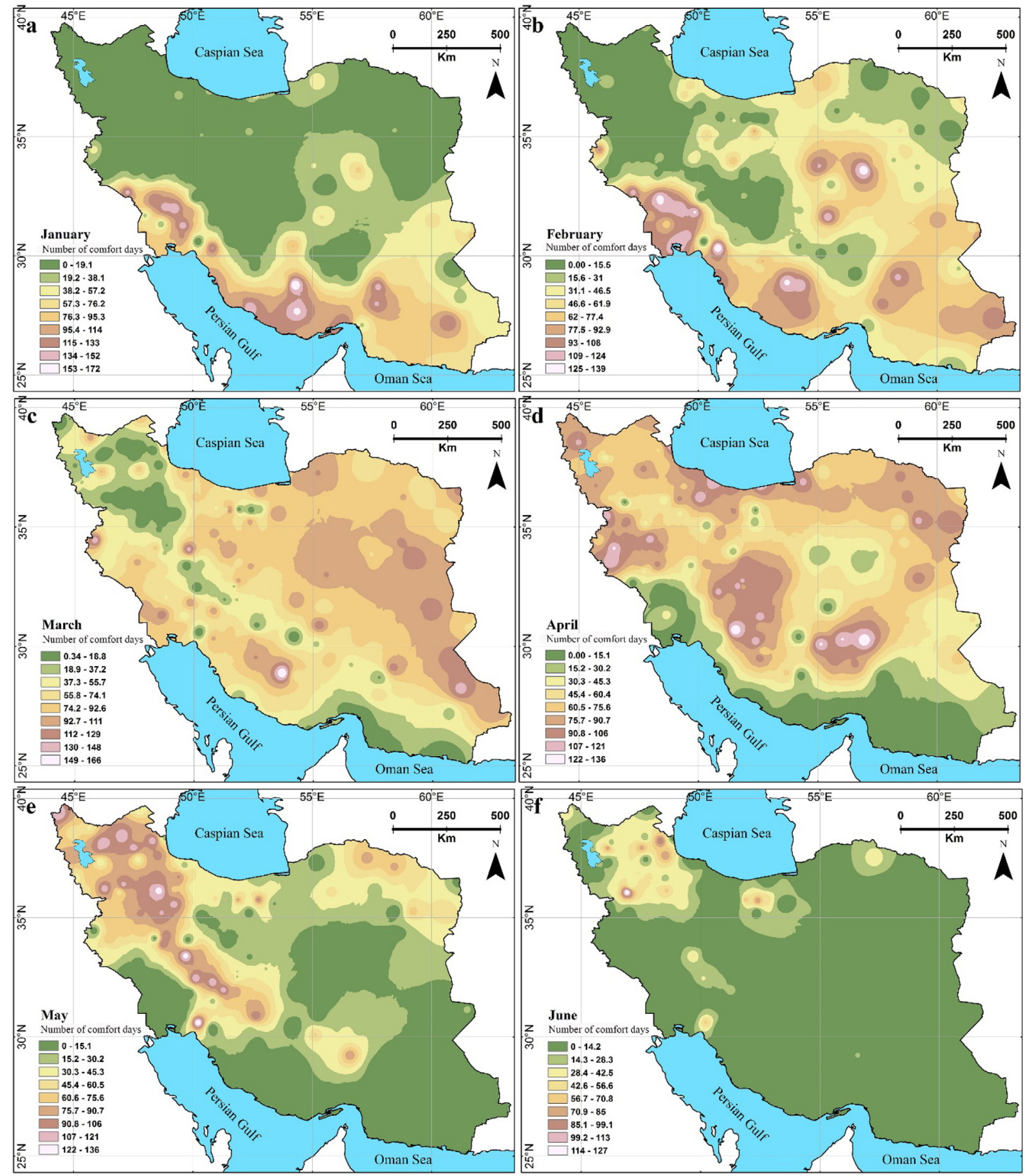

Fig. 4. Frequency of different comfort day event of the first step from the frequency of comfort days of the second step during the study period 1994 to 2014 in terms of percent. a: frequency of all comfort days without considering estimated thresholds. b: frequency of all comfort days with respect to estimated threshold.

Persian Gulf and small zones in Southeast of the country have the greatest comfort days' frequency. But the minimum comfort days are seen in the Northern Coasts of the Oman Sea and some zones in the Northeast of Iran (4b).

\section{Discussion}

In order to estimate the thermal comfort category, a statistical method that takes into account patterns of dominant climatology 


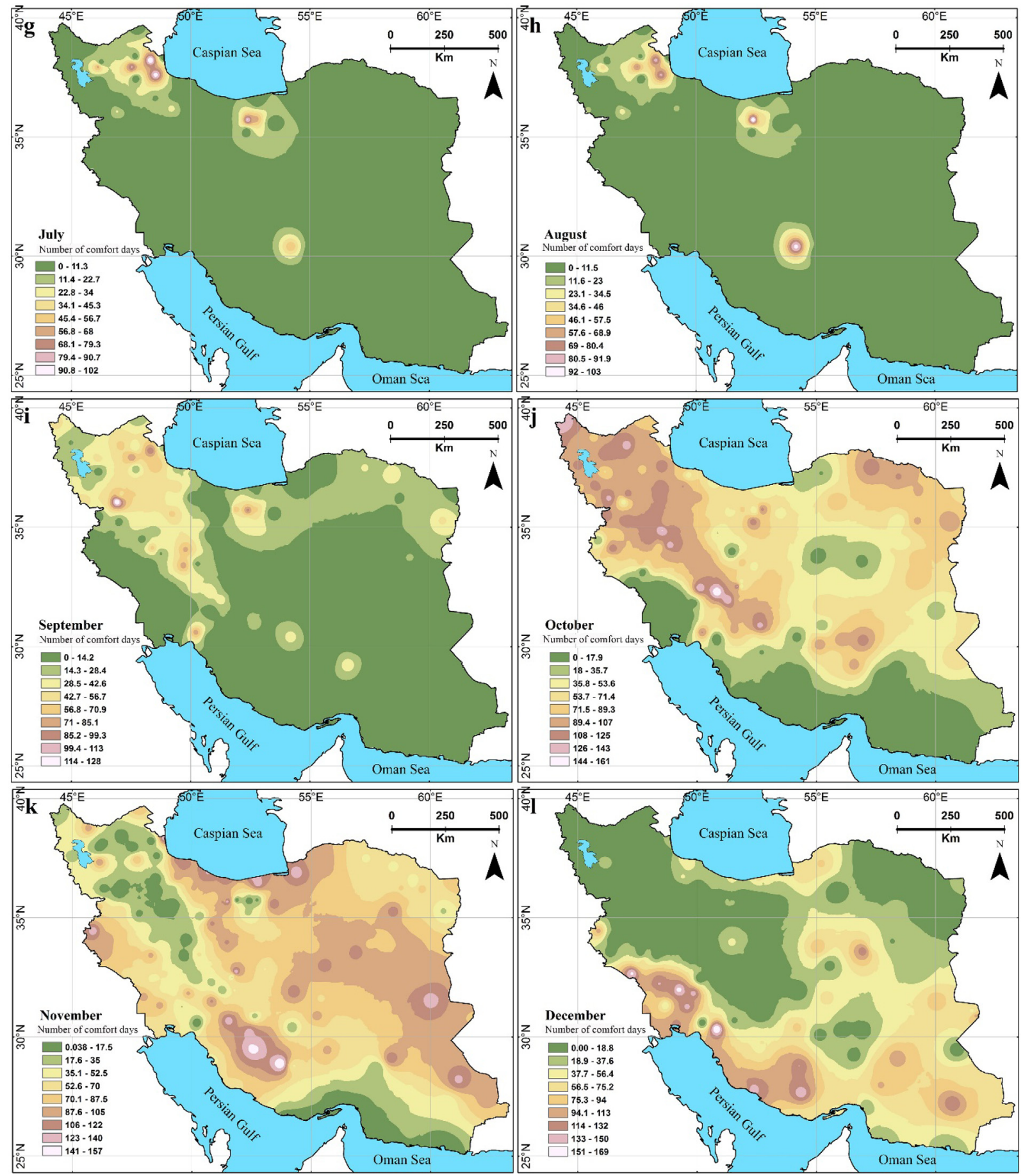

Fig. 4. (continued)

condition events of meteorological stations has been applied. According to the climatology pattern the estimated comfort zone of each station or geographical area is influenced by repetition and frequency of events for the days falling within the thermal comfort zone. Each station has different and various experiences of quantity and quality of frequency of thermal comfort days with respect to climate variation and geographical conditions. A significant contribution of this research is the introduction of the one day as a comfort day based on 4 reliable outdoor bioclimatic indices. The aim of this is to regard and/or combine the theoretical bases of different climatic indices in determining thermal comfort conditions. This methodology can be repeated in other countries too.

In most previous works, the estimate of thermal comfort category has been approached from a different point view. One of the closest studies to this study is the work of Roshan Gh and Attia (2017). According to their work, dominant patterns of comfort 
temperatures were introduced for basic thermal comfort temperatures. However, they used Olgyay's diagram for presenting thermal comfort temperature. In Olgyay's diagram, the comfort zone just depends only on two variables: temperature and relative humidity. While in this work, more climatic variables and thermo-physiological indices have been used, to specify comfort category thresholds.

Moreover, the spatial variance of the estimated comfort category for indices PET, UTCI and PT is low. The work of Farajzadeh et al., 2015 investigated the connection and coefficient among bioclimatic indices results for the Northwest of Iran. Farajzadeh et al. (2015) compared UTCI outputs with some simple and thermo-physiological indices. The results of their work showed that the maximum of correlation among thermo-physiological indices, relating to PET and UTCI, is similar to our investigation. Also, our findings agree with the results of Błażejczyk et al. (2012), who concluded that the values for the indices derived from human energy balance models (i.e., PET) were most similar to those of UTCI because these indices indicate equivalent temperature. On the other hand, some studies across the world have been conducted in order to compare bioclimatic and thermo-physiological indices. For example, Abdel-Ghany et al. (2013) applied two indices UTCI and PET to investigate bioclimatic condition in dry climatic areas. Bröde et al. (2013) showed that the UTCI is highly sensitive to relative humidity and radiation in hot lands and wind speed in cold areas. They evaluated the three indices namely UTCI, Predicted Heat Strain (PHS) and wet bulb globe temperature (WBGT). Their findings showed that the use of UTCI index in evaluating cold and hot stresses condition is acceptable. A rapid drop in the values of UTCI were recorded when wind speed was increased. This was in accordance with the results of Novak (2013) and Nowosad et al. (2013), showing that UTCI index reflected the impact of a variety of meteorological variables on the heat balance of human body in a thermo-physiological manner similar to PET index. Thus, this index enables general meteorological information to be transformed into an evidence for human biometeorological applications (e.g., for assessing tendencies of heat stress or to cold stress). In another study for Iran, Roshan et al. (2016c) investigated the results of the two PT and PET indices. The outputs showed that the PET thresholds are more sensitive to cold and hot bioclimatic categories investigation than PT. This factor caused that more days were placed on comfort category in comparison to PET.

The findings of our research confirm that different bioclimatic indices provide different occurrence frequencies of comfort days. A study concerning some Iranian cities showed that the correlation of results for PET and PT method was not significant (Zamanei et al., 2010). In a research project presented by Tahbaz (2010), thermal indices such as Temperature Humidity Index (THI), perceived temperature (PT), Discomfort Index (DI), Tropical Summer Index (TSI), Wet Bulb Globe Temperature (WBGT), physiologically equivalent temperature (PET), and Universal Thermal Climate Index (UTCI) were studied and compared together in a psychrometric chart (Tahbaz, 2010). In this study, these indices were found not in accordance with each other. Therefore, using an index for a specific project in a city needs to be clarified by means of local observations to explore which index would be more suitable for predicting the thermal conditions of the study site.

Results of this study showed the maximum frequency of thermal comfort days for cold seasons of the year. Fall and winter relates to coasts of the Persian Gulf and the Oman Sea. In hot seasons of the year, including spring and summer, the maximum focus of days goes along with thermal comfort condition which relates to the Northwest of Iran, and also to the Zagros Mountains and Northeast Altitudes of Iran. In another studies for Iran, these parallel results are properly observed. Roshan et al. (2016b) showed that the cities located on the coast of the Persian Gulf and the Oman Sea have the most climate conditions for tourism in winter due to warm temperatures, clear skies, and rare occurrence of precipitation. The findings of Daneshvar et al. (2013) showed that spring months, especially April, had the most appropriate condition for thermal comfort in most regions of Iran, although, in southern cities, the comfort conditions were related to winter. Also, Daneshvar et al. (2013) used long-term average monthly data to estimate PET index and examined thermal comfort conditions during different months of the year. Their results showed that thermal comfort conditions prevail during the winter months on the southern part of the country and along the shores of the Persian Gulf and the Oman Sea. It was determined that, in some studies to survey the most ideal item for tourism in the Northwest of Iran, the months from June to December are the most proper conditions in terms of bioclimatic factors for tourism (Farajzadeh and Matzarakis, 2009, 2012). The results of our study, too, present the same period with a slight difference as the most ideal bioclimatic condition.

As mentioned before, the comfort zones estimated in this work always result in a more narrowed interval, when considering the original ranges originally established for each one of the indices studied. They are an approximation and, for a more precise approach, calibrating each index for a local population is necessary. The studies about revising individuals, thermal perception in different areas is growing (Hwang et al., 2010; Krüger et al., 2011; Lin et al., 2013; Yang et al., 2013). Besides behavioral factors (e.g., adaptive behavior to restore the heat balance and previous activities), physical factors (e.g., actual weather conditions), and psychological factors (e.g., thermal history and expectations) also play important roles in assessing the influence of thermal environments on human comfort (De Dear and Brager, 1998; Nikolopoulou et al., 2001; Lin, 2009; Yang et al., 2013; Wang et al., 2017). In a study for Glasgow, it became distinct that the optimal threshold for thermal comfort condition PET is lower than common threshold 18 to 23 and these ranges include 9 to $18{ }^{\circ} \mathrm{C}$. Yet, Matzarakis et al., 2012 for the Alps Australia, Brosy et al. (2014) for Croatia and Matzarakis (2007) Crete- Greece commonly introduced threshold 18 to $29^{\circ} \mathrm{C}$ as the comfort category of PET index, and for Taiwan it became distinguished that the threshold 22 to $34^{\circ} \mathrm{C}$ would be the proper comfort thermal category (Lin and Matzarakis, 2008). Hirashima et al. (2018) present a comparison of the calibrated PET index for Brazilian and German cities; meanwhile Hirashima et al. (2016) present the calibration of the PET index for Belo Horizonte, Brazil. As it is observed, in different countries and different areas of Europe, the thermal comfort category PET includes some different ranges that may be wider or narrower than the original ranges, or those ranges may even be displaced to some hotter or colder conditions. To better evaluate this issue, a calibration of the index, considering microclimatic measurements and forms/questionnaires administration is required, as shown in the work of Hirashima et al. (2016).

In the present study, we proofed that the comfort category thresholds for all different areas of Iran are different in relation to one another. It is scarcely possible to specify similar thresholds of comfort categories for different stations. However, the difference of 
thresholds of obtained comfort category for Iran is distinct from other studies in the World. The applied methodology basics in these methods differ mainly in relation to each other. We only considered the dominant patterns of comfort category while other studies focus on the individuals, feedback in different bioclimatic condition and determining the calibrated comfort category. Therefore, it seems that the combination of these two methods could offer more proper survey than thermal comfort condition for different parts of the World in the upcoming studies.

\section{Conclusion}

This paper presented the estimate of the approximate maximum and minimum values of the outdoor thermal comfort zone of four thermal comfort indices for different climatic regions in Iran. The research findings show that the general mean of the high threshold of comfort category based on selected stations of Iran for PET and SET* include $22.16^{\circ} \mathrm{C}$, and $24.28{ }^{\circ} \mathrm{C}$ and for UTCI and PT includes $23.68^{\circ} \mathrm{C}$ and $17.82^{\circ} \mathrm{C}$. On the other hand, the general mean of low thresholds of estimated comfort category for indices PET and SET* includes $19.64{ }^{\circ} \mathrm{C}$ and $21.90^{\circ} \mathrm{C}$ respectively; and this output for UTCI and PT includes $20.65{ }^{\circ} \mathrm{C}$ and $16.16{ }^{\circ} \mathrm{C}$. According to the index PET, it was observed that the, the maximum of high threshold relates to northern areas of the Oman Sea and then the Northern Coast of Persian Gulf. With respect to this index, one maximum zone is also seen in the Northeast of Iran. Results of the present study showed that the maximum of the high estimated threshold for SET*, like PET, belongs to two zones for the Northeast and Southwest of Iran. In addition, the findings showed that for UTCI and PT, like to PET, the maximum of high threshold of the estimated comfort category are considered for the Southern Coast of Iran.

Therefore, among such indices, behavior of SET* is slightly different from other indices. For PET, the minimum boarder of low threshold in the zones of Southern Coasts of the Caspian Sea as the first zone has been connected to the second core that is placed on the northern half of the center of Iran and the third core, including the southwest of Iran. According to the index SET*, the maximum zone of low estimated threshold of central Iran, in the remaining areas, the concentration of the low estimated threshold minimum is observed. On the other hand, the minimum distribution of low threshold for PT relates to the Caspian Sea coasts and disparate and small cores on the Zagros Mountains. Thus, on the basis of findings of the study, it is observed that the pattern of spatial distribution of low threshold minimum based on different indices does not follow an equal behavior. With attention to the changes of the threshold zone of the estimated comfort category of the indices studied. About the index SET*, after determining the comfort category, it became specified that its zone for Iran varies from $20.45^{\circ} \mathrm{C}$ to $25.44{ }^{\circ} \mathrm{C}$, and also that the high estimated thresholds distance in relation to $30^{\circ} \mathrm{C}$ for most stations is greater than the low estimated thresholds distance in relation to $17^{\circ} \mathrm{C}$. However, for UTCI, the estimated band zone has varied from the least $18.47^{\circ} \mathrm{C}$ to the most $25.03^{\circ} \mathrm{C}$. In the rest, the finding of the study showed that the low threshold of the estimated comfort category was severely from $9{ }^{\circ} \mathrm{C}$, and skewed estimated comfort category for the selected stations tends to greater amounts or high threshold.

Consequently, the band zone for the PT index can be pointed out. The zone of this band varied from the least $15.93{ }^{\circ} \mathrm{C}$, to $19.10{ }^{\circ} \mathrm{C}$, but it can be understood from the findings of this research that the skew of the estimated comfort category for the entire stations tends to high thresholds $20^{\circ} \mathrm{C}$. To put it simpler, the distance of low estimated thresholds in relation to zero is much greater than the distance of high estimated thresholds in relation to $20^{\circ} \mathrm{C}$. The conclusions based on the thresholds of estimated comfort category indicated that for indices PET, UTCI and PT, the inclination and skew of comfort category tend to high thresholds whereas for SET*, this skew for most stations tends to the threshold of comfort category. The decreasing changes minimum relate to the coasts of the Persian Gulf and the Oman Sea, when removing the thermal comfort days in cold seasons- autumn and winter. In the spring and summer, the minimum of these decreasing changes belong to the Northwest of Iran and the Zagros Mountains and Northeast of Iran.

On the building level, the indoor environment is highly dependent on climate conditions outside (Attia, 2006; Attia, 2016). It is expected that, based on the estimated bioclimatic comfort zone of the study stations, one could have a more appropriate estimate of the amount of energy supply and demand to provide environmental comfort inside buildings. Heating and cooling energy risk management of the urban settlements can be done with more rational criteria. It is also expected that these new comfort zones can be considered in the architectural design of buildings and planning of heating and cooling installation systems in different climatic zones of Iran in order to reduce extra costs of energy supply. Future work will focus on identifying solar passive features related to building form and orientation, envelope design, shading, use of natural ventilation, internal space arrangements and activities of the habitants for all the climatic zones of Iran.

As it was mentioned before, the comfort intervals identified in this study differ from real intervals due to the adaptive process of the population, though its use represents an important contribution for estimating the thermal comfort ranges for a given location. Our use of statistical technique, using macro scale data from meteorological data and the indices calibration process are complementary, it is highly recommended that, in a first moment, the definition of the thermal comfort zone be made, by using this proposed methodology, which is based on available, usual and low-cost data. Then, in a second moment, it must be detailed using the calibration process. Therefore, it is of extreme relevance that future studies be carried out in order to calibrate these indices, by using data collected during field studies together with the application of forms/questionnaires, aiming to define all the thermal comfort ranges with higher accuracy.

Finally, it is expected that based on the calibrated bioclimatic comfort zone of the study stations, one could have a more appropriate estimate of the amount of energy supply and demand to provide environmental comfort inside buildings. This includes heating and cooling energy risk management of the urban settlements can be done with more rational criteria. Also it is expected that these new comfort zones can be considered in the architectural design of buildings and planning of heating and cooling installation systems in different climatic zones of Iran in order to reduce extra costs of energy supply. 
Appendix A. Appendix

Table 4

Low and high thresholds estimated for the four bioclimatic indices.

\begin{tabular}{|c|c|c|c|c|c|c|c|c|}
\hline \multirow[t]{2}{*}{ Stations } & \multicolumn{4}{|c|}{ High thresholds } & \multicolumn{4}{|c|}{ Low thresholds } \\
\hline & PET & $\mathrm{SET}^{*}$ & UTCI & PT & PET & SET* & UTCI & PT \\
\hline Abade & 22.28 & 24.44 & 23.42 & 17.62 & 19.75 & 21.87 & 20.37 & 16.07 \\
\hline Abali & 22.14 & 23.94 & 23.82 & 17.37 & 19.78 & 21.69 & 21.13 & 16.04 \\
\hline Abumusa & 22.00 & 23.12 & 24.38 & 18.88 & 19.34 & 20.81 & 21.60 & 16.35 \\
\hline Ahar & 22.22 & 24.33 & 24.42 & 17.70 & 19.85 & 22.14 & 21.55 & 16.09 \\
\hline Ahvaz & 21.63 & 23.38 & 23.41 & 18.18 & 18.92 & 20.45 & 20.00 & 15.98 \\
\hline Aligudarz & 22.10 & 23.18 & 23.88 & 17.34 & 19.70 & 21.13 & 21.83 & 16.05 \\
\hline Anar & 22.22 & 23.97 & 23.22 & 17.51 & 19.45 & 21.22 & 19.47 & 16.11 \\
\hline Arak & 22.20 & 24.78 & 23.33 & 17.72 & 19.58 & 22.15 & 20.09 & 16.04 \\
\hline Ardebil & 22.21 & 24.11 & 25.03 & 18.08 & 19.77 & 21.91 & 22.46 & 16.08 \\
\hline Ardestan & 22.15 & 23.51 & 23.85 & 17.49 & 19.61 & 21.13 & 20.77 & 16.12 \\
\hline Astara & 21.79 & 24.81 & 23.23 & 18.28 & 19.08 & 22.28 & 19.54 & 16.13 \\
\hline Avaj & 22.18 & 23.59 & 23.94 & 17.38 & 19.82 & 21.42 & 21.94 & 16.10 \\
\hline Babolsar & 21.94 & 24.74 & 23.95 & 18.27 & 19.14 & 22.32 & 20.32 & 16.01 \\
\hline Bafq & 22.11 & 24.02 & 23.34 & 17.62 & 19.55 & 21.42 & 19.99 & 16.13 \\
\hline Baft & 22.13 & 23.85 & 23.54 & 17.52 & 19.67 & 21.49 & 20.87 & 16.07 \\
\hline Bam & 22.13 & 23.97 & 23.47 & 17.58 & 19.58 & 21.42 & 20.49 & 16.14 \\
\hline Bandarabbas & 22.44 & 23.95 & 24.31 & 18.41 & 20.02 & 21.74 & 22.34 & 16.38 \\
\hline Bandare Mahshahr & 22.01 & 23.95 & 24.15 & 18.17 & 19.53 & 21.45 & 21.85 & 16.09 \\
\hline Bandare Anzali & 21.66 & 24.38 & 23.97 & 18.33 & 19.02 & 21.95 & 21.02 & 15.93 \\
\hline Bandare Dayyer & 22.06 & 23.44 & 24.27 & 18.34 & 19.55 & 21.04 & 21.95 & 16.17 \\
\hline Bandare Lengeh & 22.27 & 23.52 & 24.46 & 18.56 & 19.86 & 21.44 & 22.45 & 16.35 \\
\hline Behbahan & 22.17 & 23.46 & 23.89 & 17.36 & 19.78 & 21.23 & 21.82 & 16.11 \\
\hline Birjand & 22.23 & 24.36 & 23.49 & 17.57 & 19.73 & 22.11 & 20.23 & 16.14 \\
\hline Biyarjomand & 22.16 & 24.22 & 23.86 & 17.67 & 19.67 & 21.95 & 20.55 & 16.12 \\
\hline Bojnurd & 22.26 & 24.59 & 24.47 & 18.10 & 19.71 & 22.23 & 20.70 & 16.14 \\
\hline Borujen & 22.26 & 24.24 & 23.56 & 17.57 & 19.84 & 21.87 & 20.54 & 16.08 \\
\hline Borujerd & 22.20 & 23.88 & 23.98 & 17.45 & 19.73 & 21.56 & 21.19 & 16.07 \\
\hline Boshruyeh & 22.35 & 24.48 & 22.95 & 17.99 & 19.59 & 22.21 & 19.11 & 16.11 \\
\hline Bostan & 22.03 & 23.78 & 24.16 & 17.97 & 19.55 & 21.55 & 22.06 & 16.10 \\
\hline Bushehr-Airport & 22.19 & 24.02 & 24.58 & 18.60 & 19.67 & 21.68 & 22.33 & 16.27 \\
\hline Bushehr-Coastal & 22.05 & 23.70 & 24.71 & 18.70 & 19.42 & 21.38 & 22.52 & 16.15 \\
\hline Chahbahar- & 22.51 & 23.58 & 24.41 & 18.51 & 19.98 & 21.44 & 22.12 & 16.29 \\
\hline Dehloran & 22.02 & 24.47 & 23.44 & 18.12 & 19.40 & 21.79 & 20.47 & 16.14 \\
\hline Dezful & 22.17 & 25.09 & 23.20 & 18.56 & 19.52 & 22.52 & 19.81 & 16.31 \\
\hline Dogonbadan & 22.11 & 25.12 & 22.81 & 18.26 & 19.50 & 22.65 & 19.70 & 16.25 \\
\hline Dorudzan & 22.18 & 24.41 & 23.52 & 17.68 & 19.63 & 22.12 & 20.24 & 16.16 \\
\hline Dowshan Tappeh & 22.15 & 24.53 & 23.16 & 17.74 & 19.52 & 22.22 & 19.74 & 16.15 \\
\hline Eqlid & 22.26 & 24.05 & 23.60 & 17.49 & 19.74 & 21.70 & 20.77 & 16.08 \\
\hline Esfahan-Airport & 22.24 & 23.78 & 23.88 & 17.40 & 19.93 & 21.71 & 21.65 & 16.14 \\
\hline Esfahan & 22.22 & 24.68 & 23.23 & 17.71 & 19.62 & 22.14 & 19.73 & 16.14 \\
\hline Eslamabad-e-Gharb & 22.17 & 24.61 & 23.62 & 17.63 & 19.70 & 22.40 & 20.42 & 16.17 \\
\hline Fasa & 22.02 & 25.03 & 22.61 & 17.94 & 19.30 & 22.53 & 19.26 & 16.16 \\
\hline Ferdows & 22.22 & 24.05 & 23.68 & 17.45 & 19.82 & 21.87 & 20.86 & 16.18 \\
\hline Firuzkuh (GAW) & 22.10 & 23.94 & 23.64 & 17.31 & 19.77 & 21.58 & 21.30 & 16.06 \\
\hline Firuzkuh & 22.19 & 23.96 & 24.29 & 17.73 & 19.82 & 21.89 & 21.39 & 16.10 \\
\hline Garmsar & 22.21 & 24.52 & 23.55 & 17.77 & 19.53 & 21.83 & 19.80 & 16.18 \\
\hline Gharakhil & 21.95 & 24.79 & 24.02 & 18.16 & 19.35 & 22.30 & 20.81 & 16.12 \\
\hline Golmakan & 22.25 & 24.14 & 24.24 & 17.63 & 19.76 & 21.78 & 21.11 & 16.14 \\
\hline Golpayegan & 22.09 & 23.73 & 23.80 & 17.38 & 19.69 & 21.41 & 20.86 & 16.10 \\
\hline Gonabad & 22.27 & 24.82 & 23.02 & 17.79 & 19.62 & 22.33 & 19.35 & 16.23 \\
\hline Gonbade kavus & 22.00 & 24.74 & 23.26 & 18.13 & 19.29 & 22.33 & 19.76 & 16.13 \\
\hline Gorgan & 22.00 & 24.86 & 23.81 & 18.14 & 19.31 & 22.42 & 19.90 & 16.19 \\
\hline Hamedan-Airport & 22.20 & 24.48 & 23.73 & 17.48 & 19.73 & 22.14 & 20.66 & 16.11 \\
\hline Hamedan-Nozheh & 22.21 & 24.12 & 24.14 & 17.43 & 19.83 & 21.98 & 21.31 & 16.09 \\
\hline Darab & 22.23 & 25.44 & 22.32 & 18.20 & 19.59 & 22.80 & 19.43 & 16.37 \\
\hline Ilam & 22.09 & 24.10 & 23.75 & 17.49 & 19.65 & 21.99 & 20.79 & 16.09 \\
\hline Iranshahr & 22.20 & 23.78 & 23.61 & 17.66 & 19.90 & 21.74 & 21.55 & 16.24 \\
\hline Izeh & 22.08 & 24.98 & 22.81 & 18.06 & 19.34 & 22.51 & 19.42 & 16.23 \\
\hline Jam & 22.14 & 24.56 & 23.59 & 17.95 & 19.74 & 22.04 & 21.09 & 16.26 \\
\hline Jask & 22.47 & 23.45 & 24.59 & 18.92 & 20.16 & 21.61 & 22.58 & 16.67 \\
\hline Jiroft & 22.32 & 25.16 & 22.85 & 18.18 & 19.80 & 22.69 & 20.05 & 16.36 \\
\hline Jolfa & 22.22 & 24.81 & 23.61 & 18.00 & 19.63 & 22.37 & 19.67 & 16.28 \\
\hline Kabutarabad & 22.34 & 24.56 & 23.26 & 17.65 & 19.74 & 21.96 & 19.57 & 16.21 \\
\hline
\end{tabular}


Table 4 (continued)

\begin{tabular}{|c|c|c|c|c|c|c|c|c|}
\hline \multirow[t]{2}{*}{ Stations } & \multicolumn{4}{|c|}{ High thresholds } & \multicolumn{4}{|c|}{ Low thresholds } \\
\hline & PET & SET $^{*}$ & UTCI & $\mathrm{PT}$ & PET & $\mathrm{SET}^{*}$ & UTCI & PT \\
\hline Kahnuj & 22.17 & 24.17 & 24.11 & 18.27 & 19.56 & 21.39 & 21.23 & 16.18 \\
\hline Kangavar & 22.20 & 24.62 & 23.72 & 17.62 & 19.70 & 22.16 & 20.52 & 16.09 \\
\hline Karaj & 22.24 & 24.27 & 24.01 & 17.63 & 19.76 & 21.93 & 20.64 & 16.20 \\
\hline Kashan & 22.17 & 25.01 & 21.66 & 18.03 & 19.38 & 22.63 & 18.47 & 16.30 \\
\hline Kashma & 22.21 & 24.94 & 22.54 & 17.88 & 19.54 & 22.50 & 19.05 & 16.28 \\
\hline Kerman & 22.22 & 23.94 & 23.67 & 17.40 & 19.81 & 21.78 & 20.82 & 16.16 \\
\hline Kermanshah & 22.26 & 24.41 & 23.78 & 17.63 & 19.79 & 22.04 & 20.51 & 16.18 \\
\hline Khalkhal & 22.24 & 24.37 & 24.46 & 17.75 & 19.76 & 22.04 & 21.48 & 16.06 \\
\hline Khash & 22.10 & 23.95 & 23.58 & 17.55 & 19.62 & 21.63 & 20.41 & 16.16 \\
\hline Khodabandeh & 22.20 & 23.72 & 24.07 & 17.46 & 19.83 & 21.46 & 21.62 & 16.12 \\
\hline Khorramabad & 22.16 & 24.29 & 23.86 & 17.60 & 19.68 & 22.25 & 20.76 & 16.12 \\
\hline Khorramdareh & 22.27 & 24.20 & 24.13 & 17.69 & 19.90 & 21.98 & 21.37 & 16.15 \\
\hline Khoy & 22.21 & 24.75 & 23.62 & 17.78 & 19.61 & 22.35 & 19.95 & 16.15 \\
\hline Khur-va-biabanak & 22.32 & 25.09 & 21.93 & 18.21 & 19.68 & 22.63 & 18.51 & 16.47 \\
\hline Kish & 22.19 & 23.51 & 24.73 & 19.01 & 19.60 & 21.18 & 22.23 & 16.47 \\
\hline Konarak & 22.45 & 23.84 & 24.22 & 18.42 & 20.18 & 21.74 & 22.04 & 16.37 \\
\hline Kuhdasht & 22.07 & 24.69 & 23.52 & 17.69 & 19.54 & 22.22 & 20.31 & 16.08 \\
\hline Kuhrang & 22.22 & 24.73 & 23.10 & 17.54 & 19.76 & 22.27 & 20.23 & 16.08 \\
\hline Lar & 22.14 & 24.84 & 23.31 & 17.98 & 19.77 & 22.33 & 20.15 & 16.39 \\
\hline Lordegan & 22.14 & 24.83 & 22.78 & 17.65 & 19.39 & 22.42 & 19.31 & 16.12 \\
\hline Mahabad & 22.22 & 24.72 & 23.76 & 17.80 & 19.68 & 21.97 & 20.37 & 16.14 \\
\hline Maku & 22.13 & 24.60 & 23.80 & 17.62 & 19.65 & 22.17 & 20.62 & 16.09 \\
\hline Malayer & 22.16 & 23.91 & 23.85 & 17.35 & 19.77 & 21.73 & 21.22 & 16.08 \\
\hline Manjil & 22.02 & 24.06 & 24.37 & 18.61 & 19.39 & 21.49 & 20.61 & 16.19 \\
\hline Maragheh & 22.17 & 24.11 & 24.15 & 17.61 & 19.75 & 21.76 & 20.95 & 16.12 \\
\hline Maravehtappeh & 22.18 & 24.42 & 24.23 & 17.96 & 19.62 & 21.95 & 20.39 & 16.18 \\
\hline Marivan & 22.28 & 24.91 & 23.58 & 17.82 & 19.66 & 22.35 & 20.23 & 16.14 \\
\hline Marvast & 22.09 & 23.87 & 23.56 & 17.49 & 19.73 & 21.19 & 21.07 & 16.13 \\
\hline Mashhad & 22.13 & 24.27 & 24.04 & 17.59 & 19.75 & 22.16 & 20.85 & 16.13 \\
\hline Masjedsoleyman & 22.12 & 25.30 & 23.02 & 18.43 & 19.53 & 22.59 & 19.92 & 16.35 \\
\hline Meshkinshahr & 22.16 & 24.71 & 23.75 & 17.75 & 19.60 & 21.80 & 20.58 & 16.06 \\
\hline Mianeh & 22.15 & 24.76 & 23.52 & 17.84 & 19.58 & 22.30 & 19.83 & 16.17 \\
\hline Minab & 22.18 & 23.48 & 23.57 & 17.80 & 19.68 & 20.82 & 21.39 & 16.15 \\
\hline Naein & 22.12 & 23.38 & 23.81 & 17.37 & 19.70 & 21.07 & 21.24 & 16.12 \\
\hline Nahavand & 22.08 & 24.54 & 23.63 & 17.56 & 19.68 & 22.04 & 20.43 & 16.11 \\
\hline Natanz & 22.20 & 24.15 & 23.59 & 17.48 & 19.64 & 21.72 & 20.05 & 16.12 \\
\hline Nehbandan & 22.12 & 24.63 & 22.87 & 17.69 & 19.53 & 22.29 & 19.47 & 16.24 \\
\hline Neyshabur & 22.25 & 24.85 & 23.58 & 17.82 & 19.60 & 22.37 & 19.79 & 16.13 \\
\hline Nowshahr & 21.94 & 24.51 & 24.43 & 18.24 & 19.32 & 22.11 & 21.00 & 16.13 \\
\hline Omidiyeh & 22.08 & 24.25 & 24.08 & 18.16 & 19.52 & 21.60 & 21.28 & 16.15 \\
\hline Orumiyeh & 22.21 & 24.45 & 24.22 & 17.47 & 19.94 & 22.35 & 21.46 & 16.06 \\
\hline Parsabad & 22.12 & 24.99 & 23.75 & 18.16 & 19.40 & 22.42 & 19.90 & 16.10 \\
\hline Piranshahr & 22.24 & 24.48 & 23.90 & 17.71 & 19.68 & 21.97 & 20.32 & 16.08 \\
\hline Poldokhtar & 22.19 & 24.14 & 23.70 & 17.76 & 19.61 & 21.64 & 19.82 & 16.22 \\
\hline Qaen & 22.12 & 24.60 & 23.11 & 17.60 & 19.45 & 22.19 & 19.80 & 16.03 \\
\hline Qazvin & 22.16 & 24.86 & 23.30 & 17.73 & 19.49 & 22.54 & 19.80 & 16.07 \\
\hline Qeshm & 22.27 & 23.79 & 24.50 & 18.72 & 19.82 & 21.55 & 22.40 & 16.43 \\
\hline Qom & 22.21 & 24.39 & 23.75 & 17.74 & 19.64 & 21.96 & 20.22 & 16.20 \\
\hline Qorveh & 22.14 & 23.84 & 23.82 & 17.33 & 19.82 & 21.49 & 21.32 & 16.14 \\
\hline Quchan & 22.19 & 24.77 & 23.81 & 17.78 & 19.74 & 22.40 & 20.27 & 16.15 \\
\hline Rafsanjan & 22.11 & 23.13 & 23.77 & 17.35 & 19.66 & 20.98 & 21.32 & 16.12 \\
\hline Ramhormoz & 22.26 & 24.72 & 23.63 & 18.25 & 19.77 & 22.20 & 20.86 & 16.34 \\
\hline Ramsar & 21.93 & 24.55 & 24.23 & 18.23 & 19.31 & 22.20 & 20.90 & 16.07 \\
\hline Rasht & 21.73 & 24.84 & 23.30 & 18.49 & 19.06 & 22.03 & 19.95 & 16.15 \\
\hline Ravansar & 22.26 & 24.43 & 23.76 & 17.61 & 19.75 & 22.00 & 20.44 & 16.13 \\
\hline Robate-poshtebadam & 22.18 & 23.63 & 23.62 & 17.39 & 19.76 & 21.38 & 21.26 & 16.17 \\
\hline Sabzevar & 22.22 & 23.89 & 24.09 & 17.60 & 19.80 & 21.68 & 21.24 & 16.15 \\
\hline Safiabad & 22.13 & 25.13 & 23.44 & 18.52 & 19.54 & 22.50 & 20.05 & 16.38 \\
\hline Sahand & 22.14 & 23.38 & 23.95 & 17.92 & 19.75 & 21.30 & 21.75 & 16.08 \\
\hline Sanandaj & 22.10 & 24.55 & 23.58 & 17.59 & 19.60 & 22.13 & 20.46 & 16.04 \\
\hline Saqez & 22.20 & 24.21 & 23.97 & 17.44 & 19.88 & 21.93 & 21.31 & 16.14 \\
\hline Sarab & 22.26 & 24.23 & 24.51 & 17.75 & 19.76 & 22.04 & 21.53 & 16.04 \\
\hline Sarakhs & 22.09 & 24.77 & 23.60 & 17.87 & 19.47 & 22.02 & 20.13 & 16.14 \\
\hline Saravan & 22.07 & 23.80 & 23.54 & 17.47 & 19.64 & 21.48 & 20.90 & 16.14 \\
\hline Sardasht & 22.23 & 24.03 & 24.07 & 17.61 & 19.76 & 21.92 & 20.88 & 16.11 \\
\hline Sarpol-e-Zahab & 22.05 & 24.83 & 23.02 & 18.08 & 19.33 & 22.26 & 19.40 & 16.22 \\
\hline
\end{tabular}


Table 4 (continued)

\begin{tabular}{|c|c|c|c|c|c|c|c|c|}
\hline \multirow[t]{2}{*}{ Stations } & \multicolumn{4}{|c|}{ High thresholds } & \multicolumn{4}{|c|}{ Low thresholds } \\
\hline & PET & SET $^{*}$ & UTCI & PT & PET & SET $^{*}$ & UTCI & PT \\
\hline Saveh & 22.23 & 23.89 & 23.93 & 17.58 & 19.65 & 21.37 & 20.32 & 16.16 \\
\hline Semnan & 22.11 & 24.48 & 23.21 & 17.68 & 19.62 & 22.12 & 19.84 & 16.15 \\
\hline Shahrebabak & 22.15 & 24.04 & 23.54 & 17.39 & 19.78 & 21.78 & 20.73 & 16.13 \\
\hline Shahrekord & 22.22 & 24.77 & 23.27 & 17.62 & 19.72 & 22.27 & 20.20 & 16.06 \\
\hline Shahreza & 22.14 & 24.05 & 23.68 & 17.49 & 19.75 & 21.58 & 20.78 & 16.13 \\
\hline Shiraz & 22.03 & 24.51 & 23.18 & 17.59 & 19.43 & 22.22 & 19.86 & 16.11 \\
\hline Shushtar & 22.18 & 24.56 & 23.89 & 18.29 & 19.62 & 21.86 & 20.83 & 16.30 \\
\hline Siri island & 22.04 & 23.14 & 24.42 & 19.10 & 19.40 & 20.84 & 21.48 & 16.47 \\
\hline Sirjan & 22.22 & 24.35 & 23.58 & 17.56 & 19.68 & 21.74 & 20.36 & 16.15 \\
\hline Tabas & 22.15 & 24.96 & 21.96 & 18.14 & 19.38 & 22.55 & 18.66 & 16.31 \\
\hline Tabriz & 22.27 & 23.72 & 24.23 & 17.59 & 20.01 & 21.85 & 22.20 & 16.20 \\
\hline Takab & 22.15 & 24.52 & 23.67 & 17.51 & 19.66 & 22.09 & 20.56 & 16.03 \\
\hline Tehran(Geophysic) & 22.18 & 23.93 & 23.64 & 17.43 & 19.68 & 21.81 & 20.72 & 16.17 \\
\hline Tehran(Mehrabad) & 22.06 & 24.00 & 23.71 & 17.55 & 19.55 & 21.76 & 20.47 & 16.11 \\
\hline Tehran (Shemiran) & 22.10 & 25.01 & 22.34 & 17.78 & 19.39 & 22.62 & 19.21 & 16.13 \\
\hline Torbat-e Heydariyeh & 22.18 & 24.47 & 23.80 & 17.65 & 19.70 & 22.02 & 20.37 & 16.12 \\
\hline Torbat-e-Jam & 22.23 & 23.69 & 24.23 & 17.62 & 19.88 & 21.59 & 21.76 & 16.15 \\
\hline Yasuj & 22.20 & 24.86 & 23.04 & 17.70 & 19.69 & 22.50 & 19.96 & 16.13 \\
\hline Yazd & 22.19 & 23.83 & 23.44 & 17.39 & 19.81 & 21.71 & 20.97 & 16.18 \\
\hline Zabol & 22.10 & 23.93 & 23.67 & 17.82 & 19.49 & 21.26 & 20.39 & 16.15 \\
\hline Zahak & 22.25 & 24.38 & 23.33 & 17.85 & 19.71 & 21.56 & 20.25 & 16.24 \\
\hline Zahedan & 22.11 & 23.59 & 23.47 & 17.37 & 19.70 & 21.30 & 21.15 & 16.15 \\
\hline Zanjan & 22.16 & 24.08 & 23.97 & 17.42 & 20.02 & 22.09 & 21.73 & 16.20 \\
\hline Zarqan & 22.14 & 24.90 & 22.80 & 17.74 & 19.32 & 22.31 & 19.12 & 16.11 \\
\hline Zarrineh & 22.15 & 23.56 & 24.01 & 17.35 & 19.87 & 21.41 & 21.93 & 16.11 \\
\hline
\end{tabular}

\section{References}

Abdel-Ghany, A., Al-Helal, I.M., Shady, M., 2013. M.,1,2. Human Thermal Comfort and Heat Stress in an Outdoor Urban Arid Environment: A Case Study. https://doi. org/10.1155/2013/693541.

apud Jendritzky, G., Nübler, W., 1981. A model analysing the urban thermal environment in physiologically significant terms. Arch. Met. Geoph. Biokl. Ser.B 29, 313-326.

Attia, S., 2006. The role of landscape design in improving the microclimate in traditional courtyard buildings in hot arid climates. In: In Proceedings of 23rd International Conference on Passive and Low Energy Architecture-PLEA 2006 (pp. 22-24). PLEA-Université de Genève-groupe énergie.

Attia, S., 2016. Towards regenerative and positive impact architecture: a comparison of two net zero energy buildings. Sustainable Cities Soc. 26, 393-406. ISSN 22106707. https://doi.org/10.1016/j.scs.2016.04.017.

Błażejczyk, K., Epstein, Y., Jendritzky, G., Staiger, H., Tinz, B., 2012. Comparison of UTCI to selected thermal indices. Int. J. Biometeorol. 56, 515-535.

Bröde, P., Jendritzky, G., Fiala, D., Havenith, G., 2010. The Universal Thermal Climate Index UTCI in Operational Use. Proceedings of Conference: Adapting to Change: New Thinking on Comfort. Cumberland Lodge, Windsor, UK. London: Network for Comfort and Energy Use in Buildings.

Bröde, P., Fiala, D., Błażejczyk, K., Holmér, I., Jendritzky, G., Kampmann, B., Tinz, B., Havenith, G., 2012. Deriving the operational procedure for the Universal Thermal Climate Index (UTCI). Int. J. Biometeorol. 56 (3), 481-494.

Bröde, P., Blazejczyk, K., Fiala, D., Havenith, G., Holmer, I., Jendritzky, G., Kuklane, K., Kampmann, B., 2013. The universal thermal climate index UTCI compared to ergonomics standards for assessing the thermal environment. Ind. Health 51 (1), 16-24.

Brosy, C., Zaninovic, K., Matzarakis, A., 2014. Quantification of climate tourism potential of Croatia based on measured data and regional modeling. Int. J. Biometeorol. 58, 1369-1381.

Caldieron, J., Thitisawat, M., Polakit, K., Mangone, G., 2011. Statistical model evaluation and calibrations for outdoor comfort assessment in South Florida. In: Archit Sustain Dev Volume 1: Proceedings of the 27th International Conference on Passive and Low Energy Architecture (PLEA), Louvain-la-Neuve, Belgium, 13-15 July 2011.

Daneshvar, M.R.M., Bagherzadeh, A., Tavousi, T., 2013. Assessment of bioclimatic comfort conditions based on physiologically equivalent temperature (PET) using the RayMan model in Iran. Cent. Eur. J. Geosci. 5, 53-60.

De Dear, R.J., Brager, G.S., 1998. Thermal adaptation in the built environment: a literature review. Energ. Build. 17, 83-96.

Fanger, P.O., 1972. Thermal Comfort. McGraw-Hill Book Co., New York.

Farajzadeh, H., Matzarakis, A., 2009. Quantification of climate for tourism in the northwest of Iran. Meteorol. Appl. 16, 545-555.

Farajzadeh, H., Matzarakis, A., 2012. Evaluation of thermal comfort conditions in Ourmieh Lake, Iran. Theor. Appl. Climatol. 107, $451-459$.

Farajzadeh, H., Saligheh, M., Alijani, B., Matzarakis, A., 2015. Comparison of selected thermal indices in the northwest of Iran. Nat. Environ. Change 1, 61-80.

Gagge, A.P., Stolwijk, J.A., Hardy, J.D., 1967. Comfort and thermal sensations and associated physiological responses at various ambient temperatures. Environ. Res. $1,1-20$.

Gagge, A.P., Fobelets, A.P., Berglund, L.G., 1986. A standard predictive index of human response to the thermal environment. ASHRAE Trans. 92, 709-731.

Hirashima, S., Assis, E., Nikolopoulou, M., 2016. Daytime thermal comfort in urban spaces: a field study in Brazil. Build. Environ. 107, $245-253$.

Hirashima, S., Katzschner, A., Ferreira, D., Assis, E., Katzschner, L., 2018. Thermal comfort comparison and evaluation in different climates. Urban Clim. 23, 219-230. Höppe, P.R., 1993. Heat balance modelling. Experientia 49, 741-746.

Höppe, P.R., 1999. The physiological equivalent temperature-a universal index for the biometeorological assessment of the thermal environment. Int. J. Biometeorol. $43,71-75$.

Hwang, R.L., Lin, T.P., Cheng, M.J., Lo, J.H., 2010. Adaptive comfortmodel for tree-shaded outdoors in Taiwan. Build. Environ. 45 (8), $1873-1879$.

International Society of Biometeorology - ISB, 2001. Commission 6 for the Development of a Universal Thermal Climate Index UTCI. Meeting Report, June 7-8, 2001, Freiburg, Germany. ISB Commission, Freiburg.

Jendritzky, G., Sönning, W., Swantes, H.J., 1979. Ein objectives Bewertungsverfahren zur Beschreibung des thermischen Milieus in der Stadt- und Landschaftsplanung 
(Klima-Michel-Modell'). ARL Beiträge, n.28.

Kovács, A., Unger, J., Gál, C.V., Kántor, N., 2016. Adjustment of the thermal component of two tourism climatological assessment tools using thermal perception and preference surveys from Hungary. Theor. Appl. Climatol. 125, 113-130.

Krüger, E.L., Minella, F.O., Rasia, F., 2011. Impact of urban geometry on outdoor thermal comfort and air quality from field measurements in Curitiba, Brazil. Build. Environ. 46 (3), 621-634.

Krüger, E., Rossi, F., Drach, P., 2017. Calibration of the physiological equivalent temperature index for three different climatic regions. Int. J. Biometeorol. 1-14. Lai, D., Guo, D., Hou, Y., Lin, C., Chen, Q., 2014. Studies of outdoor thermal comfort in northern China. Build. Environ. 77, $110 \mathrm{e} 118$.

Landsberg, H.E., 1972. The assessment of human bioclimate. A limited review of physical parameters. In: World Meteorological Organization, Geneva Technical Note No 123.

Lin, T.P., 2009. Thermal perception, adaptation and attendance in a public square in hot and humid regions. Build. Environ. 44 (10), $2017-2026$.

Lin, T.P., Matzarakis, A., 2008. Tourism climate and thermal comfort in Sun Moon Lake, Taiwan. Int. J. Biometeorol. 52, 281-290.

Lin, B.S., Yu, C.C., Su, A.T., Lin, Y.J., 2013. Impact of climatic conditions on the thermal effectiveness of an extensive green roof. Build. Environ. 67, 26-33.

Matzarakis, A., 2007. Assessment method for climate and tourism based on daily data. In: Matzarakis, A., de Freitas, C.R., Scott, D. (Eds.), Developments in Tourism Climatology. Commission on Climate, Tourism and Recreation. International Society of Biometeorology, Freiburg, pp 52-58.

Matzarakis, A., Mayer, H., 1996. Another kind of environmental stress: thermal stress. WHO Newsl 18, 7-10.

Matzarakis, A., Rutz, F., Mayer, H., 2007. Modelling radiation fluxes in simple and complex environments-application of the RayMan model. Int. J. Biometeorol. 51, 323-334.

Matzarakis, A., Rutz, F., Mayer, H., 2010. Modelling radiation fluxes in simple and complex environments - Basics of the RayMan model. Int. J. Biometeorol. 54, $131-139$.

Matzarakis, A., Hammerle, M., Koch, E., Rudel, E., 2012. The climate tourismpotential of Alpine destinations using the example of Sonnblick, Rauris and Salzburg. Theor. Appl. Climatol. 110, 645-658.

Mieczkowski, Z.T., 1985. The tourism climatic index: a method of evaluating world climates for tourism. Can. Geogr. 29, 220-233.

Nikolopoulou, M., Baker, N., Steemers, K., 2001. Thermal comfort in outdoor urban spaces: understanding the human parameter. Sol. Energy 70 (3), 227-235.

Nikolopoulou, M., Bakera, N., Steemers, K., 2010. Thermal comfort in outdoor urban spaces: understanding the human parameter. Sol. Energy 84 (11), 1879-1974.

Novak, M., 2013. Use of the UTCI in the Czech Republic. Geogr. Pol. 86 (21-28.52).

Nowosad, M., Rodzik, B., Wereski, S., Dobek, M., 2013. The UTCI index in Lesko and Lublin and its circulation determinants. Geogr. Pol. 86 (1), 29-36.

Olgyay, V., Olgyay, A., 1954. Application of Climatic Data to House Design. US Housing and Home Finance Agency, Washington DC.

Parsons, K.C., 2003. Human Thermal Environments. The Effects of Hot, Moderate and Cold Environments on Human Health, Comfort and Performance. Taylor \& Francis, London.

Roshan Gh, Ghanghermeh A., Attia, S., 2017. Determining new threshold temperatures for cooling and heating degree day index of different climatic zones of Iran. Renew. Energy 101, 156e167.

Roshan, Gh., 2017. Suggestion a new base temperature for calculating the amount of energy demand based on thermal comfort indices and temperature - Physiologic. J. Earth Space Phys. (JESP) 43 (3), 601-621.

Roshan, G., Samakosh, J., Orosa, O., 2016a. The impacts of drying of Lake Urmia on changes of degree day index of the surrounding cities by meteorological modeling. Environ. Earth Sci. 75, 1387.

Roshan, G., Yousefi, R., Fitchett, J.M., 2016b. Long-term trends in tourism climate index scores for 40 stations across Iran: the role of climate change and influence on tourism sustainability. Int. J. Biometeorol. 60 (1), 33-52.

Roshan, G., Yousefi, R., Kovács, A., Matzarakis, A., 2016c. A comprehensive analysis of physiologically equivalent temperature changes of Iranian selected stations for the last half century. Theor. Appl. Climatol. https://doi.org/10.1007/s00704-016-1950-3.

Salata, F., Golasi, I., Vollaro, R.L., Vollaro, A.L., 2016. Outdoor thermal comfort in the Mediterranean area. A transversal study in Rome, Italy. Build. Environ. 96, $46 \mathrm{e} 61$.

Staiger, H., Laschewski, G., Grätz, A., 2012. The perceived temperature-a versatile index for the assessment of the human thermal environment. Part a: scientific basics. Int. J. Biometeorol. 56, 165-176.

Steadman, R.G., 1979. The assessment of sultriness. Part I: a temperature humidity index based on human physiology and clothing science. J. Appl. Meteorol. 18, $861-873$.

Taffé, P., 1997. A qualitative response model of thermal comfort. Build. Environ. 32, 115-121.

Tahbaz, M., 2010. Toward a new chart for outdoor thermal analysis. In: Proceeding of the Conference: Adapting to Change: New Thinking on Comfort, London.

Terjung, W.H., 1968. World patterns of the distribution of the monthly comfort index. Int. J. Biometeorol. 12, 119-151.

Wang, Y., Groot, R., Bakker, F., Leemans, R., 2017. Thermal comfort in urban green spaces: a survey on a Dutch university campus. Int. J. Biometeorol. 61, 87-101.

Yahia, M.W., Johansson, E., 2013. Evaluating the behaviour of different thermal indices by investigating various outdoor urban environments in the hot dry city of Damascus, Syria. Int. J. Biometeorol. 57, 615-630.

Yang, W., Wong, N.H., Jusuf, S.K., 2013. Thermal comfort in outdoor urban spaces in Singapore. Build. Environ. 59, 426-435.

Zamanei, R., Sedaghat, E., Elahei, E., 2010. Comparison of perceived temperatures and physiologically equivalent temperature for Iranian selected stations. J. ILand Use Plann. 3, 25-39 (in Persian). 